\title{
AN ENQUIRY INTO THE INCIDENCE AND PROGNOSIS OF UNDIAGNOSED ABDOMINAL PAIN TREATED IN HOSPITAL
}

\author{
E. H. RANG, M.B., B.s. \\ A. S. FAIRBAIRN, M.B., B.Chir. \\ AND \\ E. D. ACHESON, D.M., F.R.C.P. \\ Oxford Record Linkage Study, Old Road, Headington, Oxford
}

THE International Statistical Classification of Diseases, Injuries and Causes of Death contains a special section for 'symptoms and ill-defined conditions regarding which no diagnosis classifiable elsewhere is recorded'. When a survey was made in the Oxford Record Linkage Study (ORLS) to determine the conditions most commonly leading to hospital inpatient investigation and treatment, it came as a surprise to find that abdominal pain for which no definite explanation could be found (ICD rubric 785.5) was the tenth commonest cause of admission in males and the sixth commonest in females. In this area in 1966 there were 682 discharges in which unexplained abdominal pain was the final 'diagnosis' reached on the inpatient summary. This unexpected finding prompted an investigation into some of the factors affecting the incidence and prognosis of this condition.

\section{MATERIAL AND Method}

Since the beginning of 1962 certain data from the records of every birth, hospital admission and death in the population of Oxford and the surrounding area have been abstracted, coded and punched on cards and matched into cumulative files (Acheson, 1967). Using this system of linked records, which includes data on age, sex and social class, it is possible to bring together information about successive events as they happen to an individual, thus enabling his progress to be followed over a defined period.

In this survey, hospital admissions relating to the population of the ORLS area were scanned and details were obtained of all patients aged 10 years or more who were discharged from hospital with undiagnosed abdominal pain in 1962 and 1963. From the cumulative files the records of these patients were examined to make sure that no other diagnosis had been made and had not been recorded on the discharge form and to obtain information about any subsequent admissions to hospital or death occurring up to the end of 1964. Since the period of study was three calendar years, the average length of follow-up was approximately two years. For example, those people admitted on 1 January 1962 were followed for three years while those admitted on 31 December 1963 were followed for only one year.

The incidence rate used here is the two-year hospital incidence which does not take into account cases of abdominal pain occurring outside hospital. The numerator is the number of persons discharged from hospital with 'abdominal pain' once or more in 1962 and 1963. The denominator is the sum of the populations of the ORLS area in the two years concerned. The population of the area in each year was derived from estimates given by the Registrar General for each of the administrative areas covered by the ORLS. The incidence by social class refers only to males aged 15-64 and the denominator figures were obtained from the 1961 census figures for the area.

\section{INCIDENCE}

\section{RESULTS}

427 patients were discharged once or more in 1962 and 1963 in whom the final diagnosis was 'abdominal pain'. Of these, $178(41.7 \%)$ were males and 249 $(58.3 \%)$ were females. Table $I$ and Fig. 1 show the incidence rates by age and sex. The highest incidence rate for females is in the youngest age group and there is a steady decline from this rate of $1 \cdot 6 / 1,000$ to a lowest rate of $0 \cdot 4 / 1,000$ at 60 . Males have a generally lower incidence rate than females, but the male rate rises to a secondary peak of $0.9 / 1,000$ in the seventh decade, exceeding the rate for females at this age.

An analysis of incidence by social class in males 
TABLE I

NUMBER OF PERSONS ADMITTED ONCE OR MORE FOR ABDOMINAL PAIN BY AGE AND SEX AND INCIDENCE FOR POPULATION OF OXFORD RECORD LINKAGE STUDY AREA FOR 1962 AND 1963

\begin{tabular}{|c|c|c|c|c|c|c|}
\hline \multirow{2}{*}{ Age Group } & \multicolumn{2}{|c|}{ Male } & \multicolumn{2}{|c|}{ Female } & \multicolumn{2}{|c|}{ Total } \\
\hline & No. & $\begin{array}{l}\text { Rate per } \\
1,000 \text { pop. }\end{array}$ & No. & $\begin{array}{l}\text { Rate per } \\
1,000 \text { pop. }\end{array}$ & No. & $\begin{array}{l}\text { Rate per } \\
1,000 \text { pop. }\end{array}$ \\
\hline $\begin{array}{l}10-19 \\
20-29 \\
30-39 \\
40-49 \\
50-59 \\
60-69 \\
70+\end{array}$ & $\begin{array}{l}47 \\
43 \\
23 \\
15 \\
19 \\
21 \\
11\end{array}$ & $\begin{array}{l}0.9 \\
0.7 \\
0.5 \\
0.4 \\
0.5 \\
0.9 \\
0.6\end{array}$ & $\begin{array}{l}77 \\
63 \\
32 \\
27 \\
21 \\
13 \\
15\end{array}$ & $\begin{array}{l}1.6 \\
1.4 \\
1.0 \\
0.6 \\
0.5 \\
0.4 \\
0.5\end{array}$ & $\begin{array}{r}124 \\
106 \\
55 \\
42 \\
40 \\
34 \\
26\end{array}$ & $\begin{array}{l}1.2 \\
1.0 \\
0.7 \\
0.5 \\
0.5 \\
0.6 \\
0.5\end{array}$ \\
\hline Total & 179 & 0.6 & 248 & 0.9 & 427 & 0.8 \\
\hline
\end{tabular}
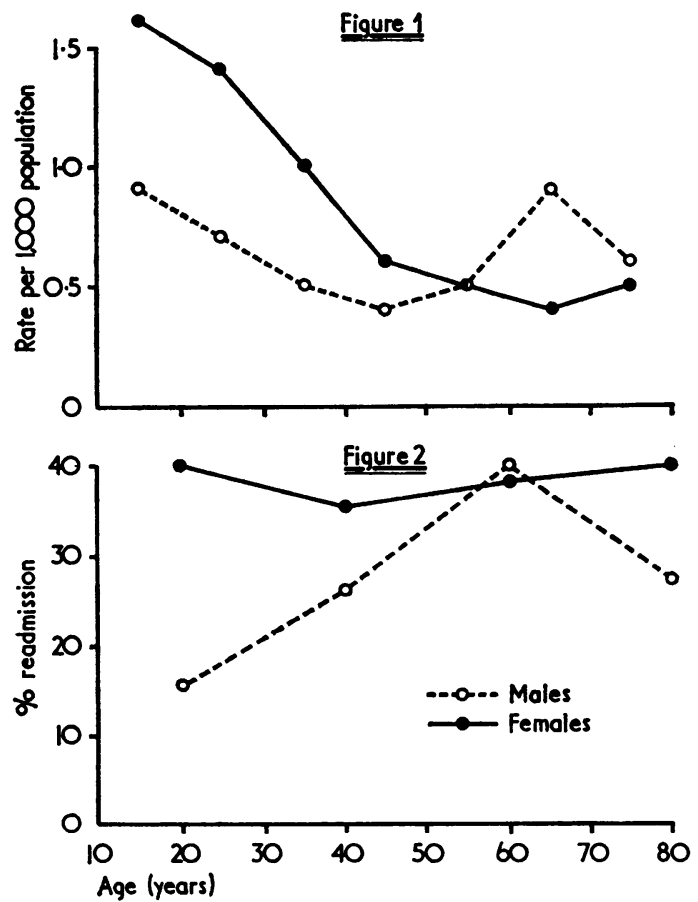

Fic. 1.-Incidence of admissions for abdominal pain by age and sex. Fio. 2.-Readmission rate after discharge with abdominal pain by age and sex.

aged 15-64 shows a rise from a rate of $0 \cdot 30 / 1,000$ in social classes 1 and 2 to one of $0 \cdot 73 / 1,000$ in classes 4 and 5 (Table II). Twenty-nine males of this age group could not be classified-1 member of the armed forces, 15 students and 13 on whom the social class was not known. However, these omissions are unlikely to affect the trend shown. Other factors investigated included marital status, source of hospital admission (for instance, waiting list or emergency) and home address, but none of these appeared to be related to the incidence.
TABLE II

INCIDENCE OF ADMISSION FOR ABDOMINAL PAIN BY SOCIAL CLASS IN MALES AGED 15-64 YEARS

\begin{tabular}{c|c|c}
\hline Social Class & No. & Rate per 1,000 Pop. \\
\hline 1 and 2 & 14 & 0.30 \\
3 and 5 & 47 & 0.46 \\
4 and & 43 & 0.73 \\
\hline Total & 104 & 0.58 \\
\hline
\end{tabular}

The majority of the patients, $85 \%$ of the males and $77 \%$ of the females, were admitted to surgicab wards. Fifteen per cent. of the males and $10 \%$ of the females were admitted to medical wards and $13 \%$ of the females to gynaecological wards. Twenty-four $(9.6 \%)$ of the females were pregnant at the time of the first admission. Using other data from the ORLS, it can be shown that in a population of this age composition one would expect 11 women $(5 \cdot 2 \%)$ to be pregnant at a given time. The excess is statistically significant. Using the same data it was found that the number of patients with an admission for abdominal pain who also experienced an admission for psychiatric reasons in the six months before the index admission or during the two-year observation period was significantly greater than expected. Thus 17 admissions for psychiatric reasons were observed while only 1.3 were expected.

\section{Prognosis}

Twenty-four per cent. of the males and $38 \%$ of the females were readmitted to hospital once or more within the follow-up period (Table III). There is a significantly higher readmission rate for females than for males but if the females who were readmitted only for obstetric reasons are omitted, the difference is no longer significant. Figure 2 shows the readmission rate by age and sex. The male readmission rate rises from a minimum of under $20 \%$ in the lower age groups to a maximum of $55 \%$ at age $50-59$. The female readmission rate remains at about $40 \%$. 
TABLE III

READMISSION RATE BY AGE AND SEX

\begin{tabular}{|c|c|c|c|c|c|c|}
\hline \multirow{2}{*}{ Age Group } & \multicolumn{2}{|c|}{ Male } & \multicolumn{2}{|c|}{ Female } & \multicolumn{2}{|c|}{ Total } \\
\hline & $\%$ Readmission & $\begin{array}{l}\text { Total No. } \\
\text { at Risk }\end{array}$ & $\%$ Readmission & $\begin{array}{c}\text { Total No. } \\
\text { at Risk }\end{array}$ & $\%$ Readmission & $\begin{array}{c}\text { Total No. } \\
\text { at Risk }\end{array}$ \\
\hline $10-19$ & $17 \cdot 0$ & 47 & $\begin{array}{c}37.6 \\
(29.9)\end{array}$ & 77 & $29 \cdot 8$ & 124 \\
\hline $20-29$ & $14 \cdot 0$ & 43 & $42 \cdot 8$ & 63 & $31 \cdot 1$ & 109 \\
\hline $30-39$ & $34 \cdot 8$ & 23 & $\begin{array}{c}43 \cdot 7 \\
(34.4)\end{array}$ & 32 & $40 \cdot 0$ & 55 \\
\hline $\begin{array}{l}40-49 \\
50-59 \\
60-69 \\
70+\end{array}$ & $\begin{array}{l}13 \cdot 3 \\
55 \cdot 2 \\
28 \cdot 6 \\
17 \cdot 3\end{array}$ & $\begin{array}{l}15 \\
19 \\
21 \\
11\end{array}$ & $\begin{array}{l}29.5 \\
42.8 \\
38 \cdot 4 \\
40 \cdot 0\end{array}$ & $\begin{array}{l}27 \\
21 \\
13 \\
15\end{array}$ & $\begin{array}{l}21 \cdot 4 \\
47 \cdot 5 \\
29 \cdot 4 \\
34 \cdot 6\end{array}$ & $\begin{array}{l}42 \\
40 \\
34 \\
26\end{array}$ \\
\hline Total & $24 \cdot 2$ & 179 & 38.3 & 278 & $32 \cdot 3$ & 427 \\
\hline
\end{tabular}

Figures in brackets refer to the readmission rate when admissions for pregnancy only are omitted.

Recurrent pain in the right iliac fossa was a common cause of readmission in young females of the second and third decades. Of those females aged $10-19,13$ out of 22 readmissions were for this condition; 6 of these were discharged again without a definite diagnosis being made or any treatment carried out and the other 7 had their appendices removed. In only 4 of the latter were the appendices considered abnormal. Of women aged 20-29, 6 out of 14 readmissions were for recurrent pain in the right iliac fossa and 2 normal appendices were removed. The readmission rate was $21.7 \%$ for those who had had their appendices removed during the index admission and $30.4 \%$ for those who had not. This difference is not statistically significant.

Table IV shows that females are significantly more likely to have an appendicectomy during their admission with abdominal pain than are males. It must be emphasized that this survey deals with patients who were discharged with the diagnosis of 'abdominal pain' even where an appendicectomy had been carried out. The implication therefore is that where an appendicectomy had been done the appendix was normal or was not thought to be the cause of the symptoms. An examination of the medical records and pathological reports of those

TABLE IV

APPENDICECTOMY RATE DURING FIRST ADMISSION

\begin{tabular}{|c|c|c|c|c|c|c|}
\hline & \multicolumn{2}{|c|}{ Males } & \multicolumn{2}{|c|}{ Females } & \multicolumn{2}{|c|}{ Total } \\
\hline & No. & $\%$ & No. & $\%$ & No. & $\%$ \\
\hline $\begin{array}{l}\text { No } \\
\text { operation } \\
\text { Operation }\end{array}$ & $\begin{array}{r}161 \\
18\end{array}$ & $\begin{array}{l}89.9 \\
10 \cdot 1\end{array}$ & $\begin{array}{r}206 \\
42\end{array}$ & $\begin{array}{l}8.3 \cdot 1 \\
16 \cdot 9\end{array}$ & $\begin{array}{c}367 \\
60\end{array}$ & $\begin{array}{l}85 \cdot 9 \\
14 \cdot 1\end{array}$ \\
\hline Total & 179 & $100 \cdot 0$ & 248 & $100 \cdot 0$ & 427 & $100 \cdot 0$ \\
\hline
\end{tabular}

patients who had had an appendicectomy but were discharged with a diagnosis of 'abdominal pain' confirmed that in all but $2 \%$ of these cases the appendix was reported as normal.

Table $\mathrm{V}$ shows the main reasons for readmission in the follow-up period. About two-thirds of the male patients and half the female patients were readmitted with abdominal conditions. An examination of the notes of those patients who had an

TABLE V

CAUSES OF READMISSION AFTER DISCHARGE WITH ABDOMINAL PAIN

\begin{tabular}{|c|c|c|c|c|c|c|}
\hline \multirow{2}{*}{ Cause } & \multicolumn{2}{|c|}{ Male } & \multicolumn{2}{|c|}{ Feniale } & \multicolumn{2}{|c|}{ Total } \\
\hline & No. & $\%$ & No. & $\%$ & No. & $\%$ \\
\hline $\begin{array}{l}\text { Abdominal pain } \\
\text { Other abdominal } \\
\text { Gynaecological } \\
\text { Psychiatric } \\
\text { Other }\end{array}$ & $\frac{15}{13}+\frac{3}{12}$ & $\begin{array}{r}34 \cdot 9 \\
30 \cdot 2 \\
\overline{6 \cdot 9} \\
28 \cdot 0\end{array}$ & $\begin{array}{r}14 \\
24 \\
12 \\
7 \\
39\end{array}$ & $\begin{array}{r}14 \cdot 6 \\
25 \cdot 0 \\
12 \cdot 5 \\
7 \cdot 3 \\
40 \cdot 6\end{array}$ & $\begin{array}{l}29 \\
37 \\
12 \\
10 \\
51\end{array}$ & $\begin{array}{r}20 \cdot 8 \\
26 \cdot 6 \\
8 \cdot 6 \\
7 \cdot 2 \\
36 \cdot 8\end{array}$ \\
\hline Total & 43 & $100 \cdot 0$ & 96 & $100 \cdot 0$ & 139 & $100 \cdot 0$ \\
\hline
\end{tabular}

admission for 'abdominal pain' followed by a psychiatric readmission showed that in most cases there was a link between the two admissions. For example, the readmission was ascribed to another ill-defined symptom ( 3 cases) or to a depressive reaction or attempted suicide (6 cases). In one case there was no obvious link between the two admissions. About $60 \%$ of the females and $70 \%$ of the males were readmitted with conditions that probably were connected with the admission for abdominal pain.

In order to compare the readmission rates after a hospital inpatient spell with the rate after admission for any reason, one of us (A.S.F.) has prepared tables showing the readmission rate by age and sex for persons admitted to hospital for any reason in 
1963 and followed up to the end of 1964. When corrected for age the overall readmission rates are $20.5 \%$ in males and $22.2 \%$ in females compared with a rate of $24.7 \%$ in males and $33.9 \%$ in females $\mathbf{2 9 . 0 \%}$ when readmissions for obstetric causes are omitted) in our study over a comparable follow-up period. Females aged 10-39 have a readmission rate of $35 \%(26.8 \%$ excluding obstetric cases) after an admission for 'abdominal pain' but only about $22 \%$ after an admission for any condition. In the age group 50-59, the readmission rates in patients with 'abdominal pain' were higher than average in both sexes $(55.2 \%$ in males and $42.8 \%$ in females as compared with $35.6 \%$ and $33.5 \%$ after admission with any condition).

There were 7 male deaths and 11 female deaths during the follow-up period. This is greater than the expected number of deaths of 1.92 males and 0.85 females over an 18-month period. All but one female death and one male death occurred in patients over 50 years of age. Four of the female deaths bore no obvious relation to the admission with abdominal pain but only one of the male deaths was not so related. The pattern of deaths thus follows the pattern of readmissions where more male than female readmissions were related to the index admission. There were 6 deaths from abdominal cancer, 3 of each sex.

\section{Discussion}

As expected, this enquiry has shown that unexplained abdominal pain is commoner in young females than in any other of the age groups in either sex. There was, however, an unexpected secondary rise in incidence in men in their sixth and seventh decades.

An examination of the clinical notes of a sample of 40 of these men showed that about one-third of them had moderate or severe upper abdominal pain with nausea or vomiting, half had mild or moderate lower abdominal pain, mainly felt on the left side, and only about $10 \%$ had pain in the right iliac fossa. This contrasted sharply with the experience of the younger men, in their second to fifth decades, in whom three-quarters had pain in the right iliac fossa or central abdomen. The appendicectomy rate was $17 \%$ in the younger decades but only $8 \%$ in the older decades, the rate tending to fall with increasing age. Five of the men who had severe upper abdominal pain were readmitted with gall bladder disease or peptic ulcers but the other $\mathbf{3 5}$ had another similar attack, with nothing abnormal found on investigation, or had no further attack. The aetiology of the episodes of pain in this group remains obscure.

A considerable number of papers and reviews have been written about the problem of diagnosis and treatment of pain in the right iliac fossa in 3 young females. Harding (1962) found that of 369웅 appendices removed for 'acute appendicitis' from $\vec{\Rightarrow}$ : female patients aged $11-30,59 \%$ were histologically $\stackrel{5}{+}$ normal, and Thackray (1959) found no difference in $\bar{C}$ the histology of appendices removed for "chronic $\frac{\bar{\sigma}}{\bar{D}}$ appendicitis' and those removed incidentally during $\frac{D}{\widetilde{D}}$ a gynaecological examination. Ingram and Evans $\_$ (1965) followed up 87 young women in whom the final diagnosis was appendicitis or pain in the right $\overrightarrow{0}$ iliac fossa for 12 months. Thirty-two of these had an abnormal appendix removed and in $90 \%$ of these $\vec{\omega}$ the pain was relieved permanently. Of the 55 patients $\stackrel{?}{?}$ who had a normal appendix, only $45 \%$ were free of pain at the end of 12 months. The more obvious $\hat{i}_{\hat{N}}$ other causes of pain in the right iliac fossa are + urinary disease, which is usually accompanied by $\overrightarrow{\vec{A}}$ other symptoms, pain of ovarian or uterine origin, $v$ usually bearing a definite relationship to the menstrual cycle, and enlargement of the ileo-caecal glands in association with a sore throat. It may be $\overparen{\mathbb{D}}$ of some interest that four of the patients in our study $\frac{0}{2}$ were readmitted for tonsillectomy during the follow-up period.

Ingram and Evans (1965) and Chaudhary ang $\vec{\varphi}$ Truelove (1962) showed that a high proportion of 0 their patients were suffering from emotional pros lems and suggested that the symptoms of pain in the right iliac fossa were due to excessive colonic $\frac{D}{\partial}$ activity. The place of appendicectomy in the treatment of young adult patients with abdominal pain $\stackrel{\varnothing}{\varnothing}$ has been the subject of a detailed study by Howie $\Rightarrow$ (1968), who favours a radical rather than a conservative approach. We have not been able to show that appendicectomy in these patients diminishes the readmission rate with abdominal pain.

It is interesting to consider possible reasons for the increase in the incidence of the condition from $0 \cdot 30 / 1,000$ in social classes 1 and 2 to $0.73 / 1,000$ in social classes 4 and 5 . The combination of poorer home conditions with inadequate telephone communications in patients from social classes 4 and 5 may make doctors more likely to send such patients into hospital for observation. There is no significant difference in the readmission rate with social class.

In both sexes there was a high readmission rate in $N$ the sixth decade. This decade also showed the largest $N$ number of readmissions with serious conditions. N Thus, 5 out of 6 patients who were readmitted with abdominal cancers were aged 50-59 years. Eighteen out of $33(54.5 \%)$ readmissions of patients of both sexes over 50 years of age were for serious conditions whereas in patients under this age only 21 out of 76 $(27.6 \%)$ were readmitted with serious conditions. A 
serious condition was defined as one in which specific treatment was required as opposed to one in which only observation and investigations were necessary.

\section{SUMmaRY}

An investigation into the incidence and prognosis of unexplained abdominal pain causing admission to hospital showed that in females there was a high incidence in the younger age groups with a steady decline thereafter, but in males the incidence rate was much lower than in females in the younger age groups but rose to a secondary peak in the sixth decade. There was a significant excess of pregnant women and people who had experienced a psychiatric admission during the period of the investigation. Twenty-four per cent. of males and $38 \%$ of females were readmitted to hospital once or more in the two-year follow-up period and both sexes showed the largest number of readmissions for serious conditions in the sixth decade. Appendicectomy does not diminish the readmission rate for abdominal pain in young females.

The Oxford Record Linkage Study has derived financial support from the Nuffield Foundation, Department of Health and Social Security and the Nuffield Provincial Hospitals Trust.

\section{REFERENCES}

Acheson, E. D. (1967). Medical Record Linkage. Published by the Oxford University Press, London, for the Nuffield Provincial Hospitals Trust.

Chaudhary, N. A., and Truelove, S. C. (1962). The irritable colon syndrome. Quart. J. Med., 31, 307.

HARDING, H. E. (1962). A notable source of error in the diagnosis of appendicitis. Brit. med. J., 2, 1028.

HowIE, J. G. R. (1968). The place of appendicectomy in the treatment of young adult patients with possible appendicitis. Lancet, 1, 1365.

INGRAM, P. W., and EvANs, G. (1965). Right iliac fossa pain in young women. Brit. med. J., 2, 149.

ThaCKRAY, A. C. (1959). "Chronic appendicitis"-some pathological observations. Brit. J. Radiol., 32, 180. 